\title{
ANÁLISE DA COBERTURA ARBÓREA DAS PRAÇAS DE CURITIBA - PR
}

\author{
ARBOREAL COVERAGE ANALYSIS IN THE PUBLIC SQUARES OF CURITIBA - PR
}

\author{
Valdir Humbeto Carcereri ${ }^{1}$, Daniela Biondi², Antonio Carlos Batista ${ }^{3}$
}

\section{RESUMO}

As praças são logradouros públicos inseridos na malha urbana, destinadas ao lazer, recreação, contemplação e convívio com a natureza. Elas são uma das tipologias de áreas verdes mais importantes em Curitiba. O presente estudo objetivou analisar a cobertura arbórea das praças de Curitiba - PR, com o intuito de verificar se elas apresentam os índices mínimos de cobertura recomendados. Foram sorteadas 33 unidades amostrais (praças) numa população de 340 unidades, com dimensões a partir de $2.250 \mathrm{~m}^{2}$, representando $9,70 \%$ das praças de Curitiba e perfazendo área total de $217.855,13 \mathrm{~m}^{2}$. A coleta das variáveis aconteceu entre agosto e dezembro de 2012. A área total de cobertura das copas foi de 45.956,55 m², sendo que a praça Abílio de Abreu apresentou a maior cobertura com 5.151,35 m². Apenas sete praças apresentaram índices de cobertura arbórea aceitáveis, representando $21,21 \%$, as outras 26 praças demonstraram índices de cobertura abaixo de $50 \%$ e representaram $78,79 \%$ do total amostrado.

Palavras-chave: Áreas verdes; Inventário arbóreo; Espaços públicos, Silvicultura urbana.

\section{ABSTRACT}

Squares are public spaces, within the urban network, for the purpose of leisure, recreation, contemplation and experiencing nature. They are some of the most important green areas in Curitiba. This research aimed to analysis the arboreal coverage in the squares of Curitiba, capital of the State of Paraná, in order to check if they have the recommended minimum levels of coverage. Thirty-three sampling units (squares) were selected from a population of 340 units, with sizes from $2,250 \mathrm{~m}^{2}$, representing $9.70 \%$ of the squares of Curitiba and performing a total area of $217,855.13 \mathrm{~m}^{2}$. The gathering of variables happened between August and December 2012. The absolute coverage of the crown was $45,956.55 \mathrm{~m}^{2}$, and Abilio Abreu square had the highest coverage with $5151.35 \mathrm{~m}^{2}$. Only seven squares showed acceptable coverage rates, representing $21.21 \%$, the other 26 squares showed coverage rates below $50 \%$ and accounted for $78.79 \%$ of all samples.

Keywords: Green areas; Tree inventory; Public spaces, Urban forestry.

Recebido em 16.04.2016 e aceito em 17.07.2016

1 Engenheiro Florestal, MSc., Secretaria Municipal do Meio Ambiente de Curitiba, Departamento de Pesquisa e Monitoramento. Curitiba/PR. Email: vcarcereri@smma.curitiba.pr.gov.br

2 Engenheira Florestal, Dra., Professora Titular do Departamento de Ciências Florestais, UFPR, Bolsista de Produtividade em

Pesquisa - CNPq, Curitiba/PR. Email: dbiondi@ufpr.br

3 Engenheiro Florestal, Dr., Professor Titular do Departamento de Ciências Florestais, UFPR, Bolsista de Produtividade em

Pesquisa - CNPq, Curitiba/PR. Email: batistaufpr@ufpr.br 


\section{INTRODUÇÃO}

O compromisso de uma cidade com a qualidade ambiental reflete-se na adoção de políticas públicas de conservação da natureza, as quais devem conciliar o desenvolvimento urbano com a preservação de áreas naturais.

Essa preocupação, observada desde o início da década de 70, confere a Curitiba especial distinção no que concerne a silvicultura urbana e proteção de áreas naturais, seja pela instituição de uma legislação ambiental apropriada e pela excepcional arborização de ruas ou ainda pela conservação de suas áreas verdes.

As áreas verdes são definidas como espaços livres urbanos compostos por vegetação arbórea e arbustiva, com solo livre de edificações ou coberturas impermeabilizantes, de acesso público ou não, e que exerçam as funções ecológicas, estéticas e de lazer (BARGOS; MATIAS, 2011).

Segundo dados da Secretaria Municipal do Meio Ambiente de Curitiba, a área dos maciços florestais de Curitiba teve um aumento significativo nos últimos dez anos, passando de $18 \%$ para $26 \%$ da área do município. Assim, o índice de áreas verdes que era de $51,5 \mathrm{~m}^{2} / \mathrm{hab}$ em 2000 aumentou para 64,5 m²/hab em 2010 (CURITIBA, 2012).

Embora o município de Curitiba apresente elevados índices de áreas verdes e possua um arcabouço legislativo para a conservação de áreas naturais, as condições climáticas vêm apresentando alterações significativas que podem comprometer a qualidade ou conforto ambiental da cidade.

Silva, Gonzales e Silva Filho (2011) analisaram diversos estudos relacionados as áreas verdes urbanas, os quais compararam áreas sem vegetação com áreas com vegetação, e notaram que estas últimas geravam ambientes urbanos com microclimas que proporcionavam melhores qualidades ambientais.

Estudos científicos realizados por Leal, Biondi e Batista (2014), Martini e Biondi (2015) corroboram e demonstram o efeito amenizador das áreas verdes na temperatura microclimática urbana. Segundo Leal et al. (2014) as regiões da cidade com maior quantidade de áreas permeáveis, concentração de remanescentes florestais ou presença de áreas verdes públicas (parques, bosques e praças) apresentaram menores temperaturas e aumento da umidade relativa do ar, atuando como "ilhas de frescor urbano".

Para embasar esta afirmação, Martini et al. (2013) comprovou estatisticamente que a cobertura arbórea da arborização de ruas de Curitiba proporciona microclimas mais agradáveis e confortáveis termicamente.

Sendo assim, para as condições adversas em que as cidades se encontram, em conjunto com as mudanças climáticas globais, as praças, sendo locais menos limitados que as 
ruas apresentam melhores condições de agregar maior cobertura arbórea e com isto proporcionar maiores efeitos benéficos no meio urbano.

As praças são espaços públicos urbanos livres de edificações que tem a função de promover convivência sadia à população, oferecendo recreação e bem-estar num ambiente agradável, além de buscar a democratização do acesso ao esporte e ao lazer, o incentivo a inclusão social e a expressão cultural (ALCANTARA; VAZQUEZ, 2015).

Biondi e Lima Neto (2012) afirmam que nas cidades, a praça é uma das tipologias de áreas verdes mais acessíveis a população urbana devido as suas funções estéticas, sociais e ecológicas.

No contexto dos aspectos ecológicos das praças de uma cidade que são relacionados principalmente com os efeitos microclimáticos, considera-se de suma importância 0 conhecimento da vegetação existente neste espaço urbano, a fim de orientar o poder público nas ações e iniciativas para a conservação do ecossistema local.

Portanto, o objetivo desta pesquisa foi analisar a cobertura arbórea das praças de Curitiba - PR, a fim de verificar se as mesmas apresentam os índices mínimos de cobertura recomendados pela literatura.

\section{MATERIAL E MÉTODOS}

A cidade de Curitiba, capital do estado do Paraná, localiza-se na região sul do Brasil, na porção leste do Estado, com latitude 25 25' 40" S e longitude 49 16' 23" W (IPPUC, 2011).

De acordo com o Instituto de Pesquisa e Planejamento Urbano de Curitiba - IPPUC, Curitiba possui 454 praças distribuídas em nove administrações regionais, totalizando uma área de 2.694.477 m² (IPPUC, 2011).

Para a realização desta pesquisa foram desenvolvidas as seguintes fases:

a) seleção, localização e sorteio das unidades amostrais (praças);

b) definição das variáveis dendrométricas para caracterização das espécies arbóreas;

c) amostragem Piloto e calculo do número de amostras necessárias

d) coleta de dados e levantamento da vegetação;

e) processamento e análise dos dados;

f) caracterização da cobertura arbórea das praças da cidade de Curitiba - PR.

Dessa forma, para atender os objetivos da presente pesquisa e com base nos conceitos existentes de praças (Robba; Macedo, 2010; Curitiba, 2012) foram consideradas como unidades amostrais as praças que apresentem as seguintes características:

a) dimensão mínima de $2.250 \mathrm{~m}^{2}$; 
b) vegetação de porte arbóreo - foram incluídos todos os indivíduos arbóreos, palmáceas e espécies vegetais que apresentaram Circunferência à Altura do Peito (CAP) igual ou maior a $15 \mathrm{~cm}$, a 1,30 m do solo, e altura superior a 2,00 m;

c) presença de equipamentos recreativos ou contemplativos;

d) não acessibilidade de veículos;

e) utilização exclusiva para pedestres.

Assim sendo, foi procedida à seleção apenas das praças que apresentassem extensões a partir de $2.250 \mathrm{~m}^{2}$ em Curitiba, totalizando 340 unidades amostrais. Posteriormente, foram localizadas as 340 unidades potenciais, utilizando-se o mapa oficial de Curitiba elaborado pelo IPPUC, na escala 1:20.000.

$\mathrm{Na}$ sequência, as mesmas foram numeradas para posterior sorteio das unidades amostrais.

O mapa a seguir apresenta a distribuição das 340 praças na cidade de Curitiba (Figura 1).

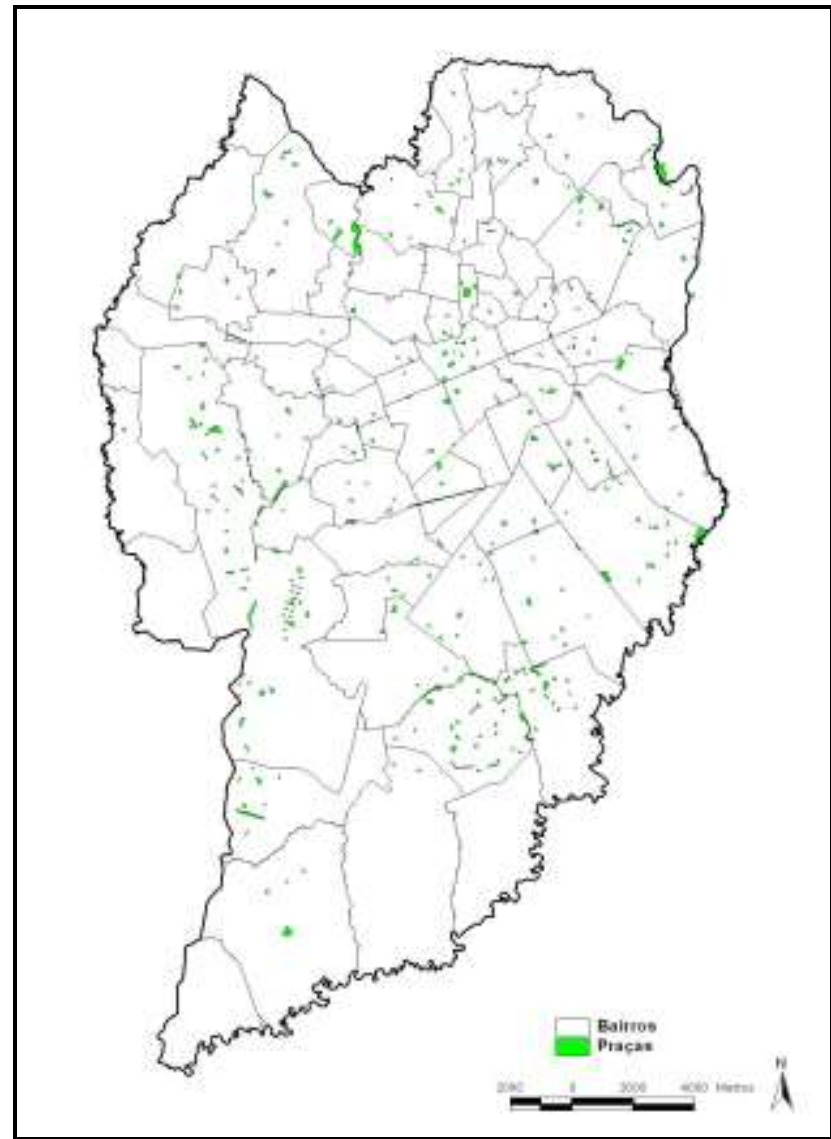

Figura 1. Localização geográfica das 340 praças em Curitiba - PR

Figure 1. Geographic location of the 340 squares in Curitiba - PR

Para obtenção das unidades amostrais procedeu-se a amostragem aleatória simples. Optou-se inicialmente pelo sorteio de 11 unidades amostrais para compor a amostragem piloto. 
No método tradicional de coleta das variáveis dendrométricas empregam-se fichas ou planilhas de campo, as quais têm a função de registrar os dados e as características relevantes do levantamento.

Portanto, para o levantamento da vegetação foi confeccionada uma planilha de campo com as variáveis de interesse, a qual foi adaptada dos modelos de Lima Neto et al. (2010), Redin et al. (2010) e Martins et al. (2011), conforme Tabela 1.

A definição do número ideal de amostras depende da variabilidade da população, portanto, faz-se necessário realizar um levantamento piloto, a fim de obter a variância da população e assim estimar a intensidade amostral necessária para o levantamento definitivo.

Tabela 1. Planilha de campo - Análise da cobertura arbórea das praças de Curitiba - PR

Table 1. Field worksheet - Analysis the arboreal coverage rates in the squares of Curitiba - PR

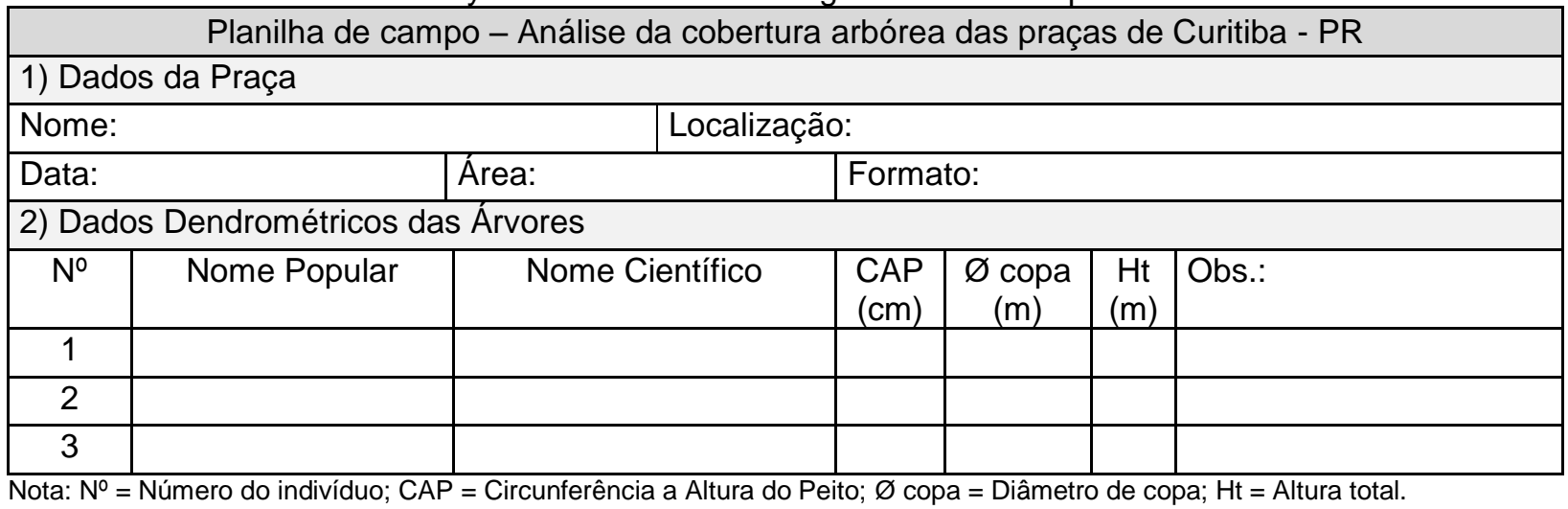

Sorteou-se 11 unidades amostrais para compor a amostragem piloto.

Sendo assim, após o piloto, os cálculos de estimativa revelaram que seriam necessários a mensuração de 33 unidades amostrais.

A coleta de dados do levantamento definitivo foi realizada no intervalo de tempo de três meses e finalizou em dezembro 2012.

Para obtenção da Circunferência à Altura do Peito (CAP) foi utilizada fita métrica de $150 \mathrm{~cm}$, modelo Fiber Glass.

Quanto à obtenção do diâmetro de copa, a fim de se ter mensuração mais precisa, foram realizadas duas medições. A primeira no sentido norte-sul e a segunda no sentido lesteoeste. Posteriormente calculou-se a média dos dois valores. Para determinação do diâmetro de copa e áreas das praças foi usada trena métrica de fibra de vidro fechada, de $50 \mathrm{~m}$, modelo Brasfort.

Os índices de cobertura de copa (projeção de cobertura arbórea) utilizados nesta pesquisa foram baseados em Lima Neto et al. (2007). 
Os dados coletados nas avaliações foram tabulados em planilha do aplicativo Microsoft Excel 2007 e os resultados apresentados em forma de tabelas e gráficos.

\section{RESULTADOS E DISCUSSÃO}

A área total amostrada (33 praças) correspondeu a $217.855,13 \mathrm{~m}^{2}$, isto representou 9,70\% das praças de Curitiba que apresentaram dimensões a partir de $2.250 \mathrm{~m}^{2}$.

A localização geográfica e distribuição das mesmas na cidade de Curitiba encontramse representadas na figura 2 .

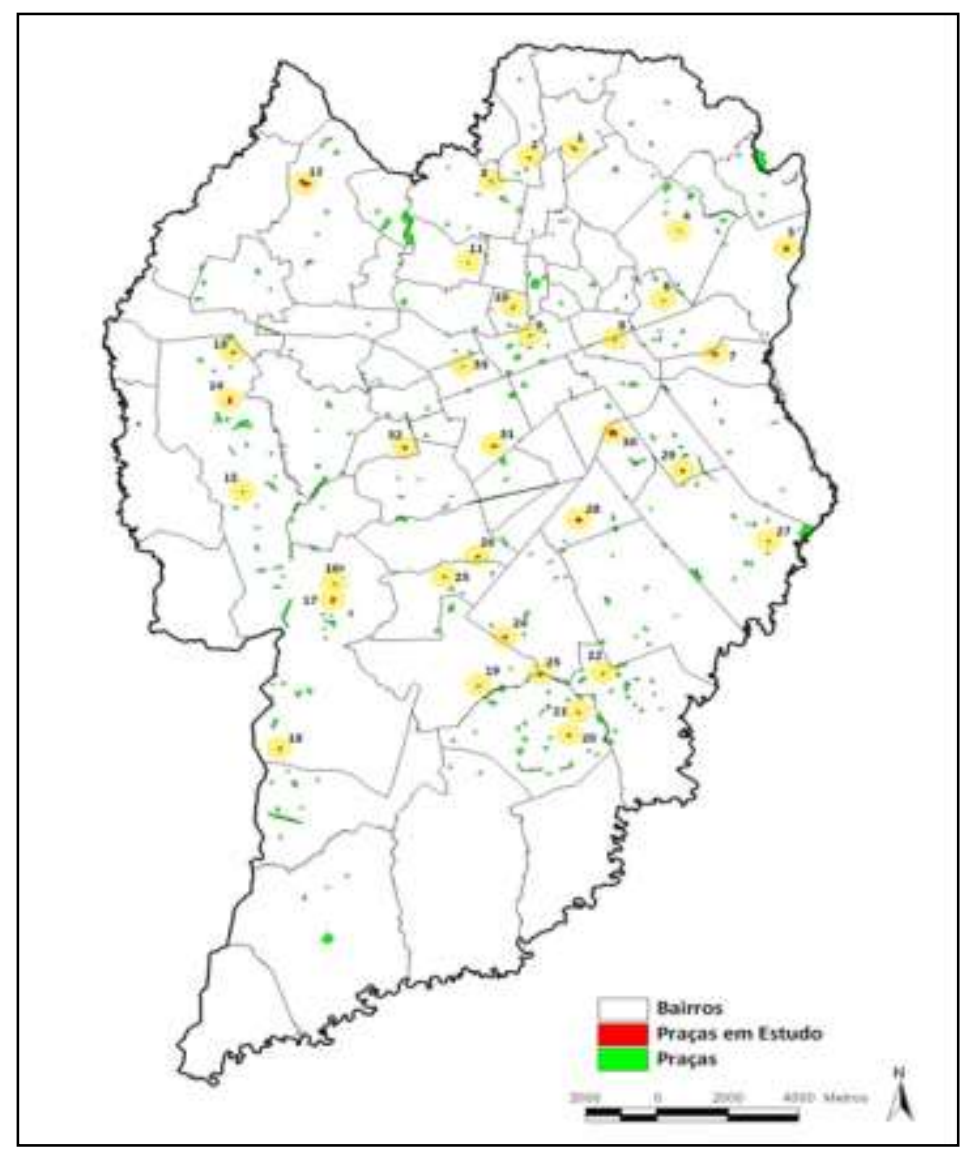

Figura 2. Localização geográfica das 33 praças amostradas em Curitiba - PR Figure 2. Geographic location of the 33 squares sampled in Curitiba - PR

Os resultados obtidos com a análise da área de projeção das copas das árvores das 33 praças amostradas estão apresentados na tabela 2 . 
Tabela 2. Área de projeção das copas das árvores existentes nas praças de Curitiba - PR

Table 2. The crown area projection of the existing trees in the squares of Curitiba - PR

\begin{tabular}{|c|c|c|c|c|c|c|}
\hline PRAÇA & $\mathrm{NI}$ & $\begin{array}{l}\text { APC } \\
\left(m^{2}\right)\end{array}$ & $\begin{array}{l}\text { ATP } \\
\left(\mathrm{m}^{2}\right)\end{array}$ & $\begin{array}{c}P \\
(\%)\end{array}$ & $\begin{array}{l}\text { CV } \\
(\%)\end{array}$ & $\begin{array}{l}\text { DENS } \\
\left(\mathrm{m}^{2} / \mathrm{ha}\right)\end{array}$ \\
\hline Abílio de Abreu & 231 & 5151,35 & 26708,71 & 19,29 & 0,70 & 1928,72 \\
\hline Elias A. Bittar & 70 & 2903,81 & 9490,58 & 30,60 & 1,11 & 3059,68 \\
\hline Július Forrer & 70 & 3014,25 & 6386,75 & 47,20 & 0,98 & 4719,54 \\
\hline Sem denominação-Uberaba & 59 & 1697,29 & 2907,44 & 58,38 & 1,02 & 5837,75 \\
\hline Francisco R. A. de Macedo & 55 & 3072,55 & 9565,59 & 32,12 & 1,23 & 3212,09 \\
\hline Sem denominação-Jd. Américas & 51 & 981,19 & 6872,16 & 14,28 & 0,92 & 1427,78 \\
\hline Villa Lobos & 45 & 2640,33 & 3220,04 & 82,00 & 0,67 & 8199,68 \\
\hline Alberto F. de Abreu & 39 & 1326,43 & 2503,86 & 52,98 & 1,05 & 5297,54 \\
\hline Antônio Bertoly & 39 & 2332,29 & 12037,95 & 19,37 & 1,00 & 1937,45 \\
\hline José V. Dias & 37 & 1240,14 & 2717,77 & 45,63 & 1,00 & 4563,08 \\
\hline Estevão Musak & 33 & 1365,15 & 3922,82 & 34,80 & 1,49 & 3480,02 \\
\hline Arthur M. Junior & 32 & 736,65 & 5178,75 & 14,22 & 1,64 & 1422,45 \\
\hline João S. Maior & 32 & 2059,83 & 2946,88 & 69,90 & 1,38 & 6989,87 \\
\hline Carlos R. Kaseker & 30 & 1104,78 & 3546,40 & 31,15 & 0,83 & 3115,22 \\
\hline Alfredo Hauer & 27 & 1477,93 & 14977,41 & 9,87 & 1,29 & 986,77 \\
\hline Donizete Custódio & 27 & 2695,89 & 2818,18 & 95,66 & 1,51 & 9566,07 \\
\hline Da Liberdade & 26 & 809,23 & 8557,91 & 9,46 & 1,56 & 945,59 \\
\hline Adolfo J. H. da Veiga & 25 & 528,15 & 13215,13 & 4,00 & 0,65 & 399,66 \\
\hline Abílio de O. Mendes & 24 & 1790,96 & 2948,93 & 60,73 & 0,89 & 6073,25 \\
\hline Carlos Filizola & 24 & 758,54 & 2502,91 & 30,31 & 0,68 & 3030,63 \\
\hline Enoch A. Ramos & 19 & 1658,20 & 9779,54 & 16,96 & 1,19 & 1695,58 \\
\hline Nelson S. Monteiro & 18 & 1382,14 & 9365,71 & 14,76 & 0,88 & 1475,75 \\
\hline Bortholo Pellanda Netto & 12 & 799,23 & 3185,17 & 25,09 & 1,34 & 2509,22 \\
\hline Lúcia B. Pillati & 11 & 601,54 & 2997,99 & 20,06 & 1,12 & 2006,48 \\
\hline Mansueden dos S. Prudente & 9 & 489,29 & 12182,05 & 4,02 & 0,31 & 401,65 \\
\hline Ronald Golias & 8 & 1428,38 & 6439,61 & 22,18 & 1,16 & 2218,12 \\
\hline Carlos R. Heller & 7 & 250,17 & 5049,48 & 4,95 & 1,52 & 495,44 \\
\hline José B. de Macedo & 7 & 1193,03 & 2698,88 & 44,20 & 1,91 & 4420,46 \\
\hline Antonio S. da C. Gebran & 6 & 103,53 & 4945,13 & 2,09 & 0,62 & 209,36 \\
\hline Das Tendas & 6 & 72,00 & 5605,89 & 1,28 & 2,46 & 128,44 \\
\hline Luiz G. C. F. dos Santos & 6 & 103,86 & 2505,76 & 4,14 & 4,25 & 414,49 \\
\hline Cícero Portes & 5 & 113,31 & 7821,79 & 1,45 & 1,47 & 144,86 \\
\hline Faraó Akhenaton & 3 & 75,13 & 2251,96 & 3,34 & 0,82 & 333,62 \\
\hline MÉDIA & 33 & 1392,62 & 6601,67 & 28,07 & 1,23 & 2807,46 \\
\hline TOTAL & 1093 & 45956,55 & 217855,13 & 926,46 & 40,65 & 92646,27 \\
\hline
\end{tabular}

O estudo apontou a existência de 1093 indivíduos distribuídos nas 33 praças de Curitiba, com uma média de 33 exemplares por unidade.

Silva e Gomes (2013), analisando espaços públicos na cidade de Arapiraca - AL, verificaram a existência de 424 árvores nos oito espaços públicos amostrados, apresentado uma média de 53 árvores. Assim, a presente pesquisa apresentou uma quantidade média abaixo do encontrado em Arapiraca. 
A praça Abílio de Abreu destacou-se apresentando a maior abundância de indivíduos, contabilizando um total de 231 exemplares. Já a praça Faraó Akhenaton apresentou a menor densidade de árvores, com apenas três indivíduos.

Nove praças (Ronald Golias, José B. de Macedo, Mansueden dos S. Prudente, Carlos R. Heller, Cícero Portes, Luiz G. C. F. dos Santos, Antonio S. da C. Gebran, Faraó Akhenaton e das Tendas) revelaram uma baixa proporção do número de árvores, com menos de dez indivíduos por praça.

Contudo, as praças Ronald Golias e José B. de Macedo, apesar do baixo número de árvores, apresentaram altos valores de projeção de copa com 1.428,38 m² e 1.193,03 m², respectivamente. Esses valores estão associados a existência de exemplares de Tipuana tipu (Benth.) Kuntze (tipuana) e Eucalyptus camaldulensis Dehnh. (eucalipto-de-camalduli), espécies de grande porte e com amplas projeções de copa, as quais contribuíram positivamente para os valores de projeção de copa.

Constatou-se que a área total de projeção de copa das praças foi de 45.956,55 m², sendo que a praça Abílio de Abreu apresentou a maior área de projeção com 5.151,35 m² e a praça das Tendas a menor área com $72,00 \mathrm{~m}^{2}$.

A avaliação da área de projeção da copa permite um diagnóstico do espaço ocupado pelas árvores e sua interação com o espaço urbano. Tais informações possibilitam a adequação do espaçamento que deve existir entre as árvores, sua posição no meio urbano, além da informação quantitativa de área verde em $\mathrm{m}^{2}$ proporcionada pela arborização.

Harder, Ribeiro e Tavares (2006) verificaram que a área total de copas encontradas nas 22 praças do Município de Vinhedo - SP foi de 25.428,45 $\mathrm{m}^{2}$. Souza (2011), estudando as áreas verdes da cidade de Recife - PE, constatou área total das copas de 21.830,93 m².

Comparando os dois estudos acima com os resultados obtidos nessa pesquisa, observou-se que a área total de projeção da cobertura arbórea das praças de Curitiba foi superior as duas cidades, sendo mais que o dobro de área de copa de Recife.

Reconhecendo o benefício que a cobertura arbórea traz ao ambiente urbano, pode-se assegurar da necessidade de novos plantios de adensamento em áreas livres desprovidas de árvores, especialmente nas praças Faraó Akhenaton e das Tendas, as quais apresentaram os menores valores de área de projeção de copa com 75,13 $\mathrm{m}^{2}$ e $72,00 \mathrm{~m}^{2}$, respectivamente (Figura 3). 


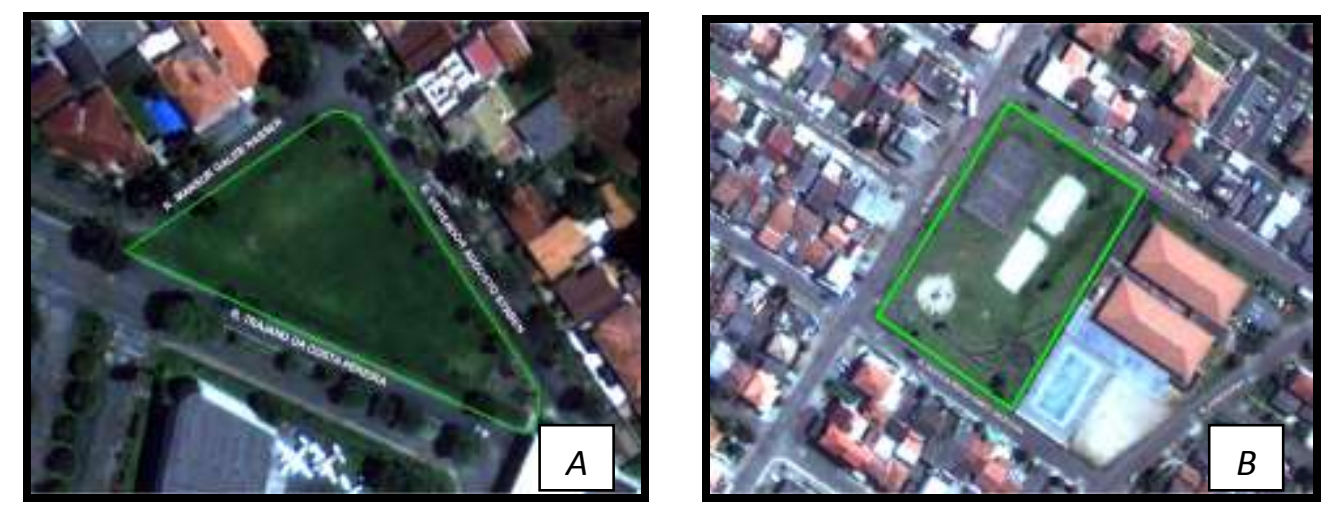

Figura 3. Praças com menores proporções de projeção da copa em relação a área total: (A) Faraó Akhenaton e (B) das Tendas

Figure 3. Squares with smaller proportion of crown projection in relation to total area: (A) Faraó Akhenaton and $(B)$ das Tendas

Observando a imagem aérea das duas praças e comparando suas dimensões (2.251,96 $\mathrm{m}^{2}$ e 5.605,89 $\left.\mathrm{m}^{2}\right)$, verifica-se que as mesmas possuem baixa cobertura arbórea, as quais poderiam receber um adensamento maior de árvores ou ter árvores de grande porte com copas amplas em razão do espaço livre disponível.

$\mathrm{Na}$ figura 4 podem-se comparar as áreas totais das praças em relação a área de projeção da copada, evidenciando a falta de cobertura florestal nessas áreas, pois as cinco maiores praças apresentaram menos de $50 \%$ de cobertura arbórea, como é o caso das praças Mansueden dos S. Prudente, Adolfo J. H. da Veiga, Alfredo Hauer, Antonio Bertoly e Abílio de Abreu.

As Praças Abílio de Abreu, Francisco R. A. de Macedo, Július Forrer e Elias A. Bittar destacaram-se neste estudo com os maiores valores de área de projeção de copa, com $5.151,35 \mathrm{~m}^{2}, 3.072,55 \mathrm{~m}^{2}, 3.014,25 \mathrm{~m}^{2}, 2.903,81 \mathrm{~m}^{2}$, respectivamente.

Os menores valores da área de projeção da copa obtidos foram para as praças Cícero Portes, Luiz G. C. F. dos Santos, Antonio S. da C. Gebran, Faraó Akhenaton e das Tendas com $113,31 \mathrm{~m}^{2}, 103,86 \mathrm{~m}^{2}, 103,53 \mathrm{~m}^{2}, 75,13 \mathrm{~m}^{2}$ e 72,00 $\mathrm{m}^{2}$, respectivamente.

Os resultados reforçam o argumento de déficit de cobertura arbórea, especialmente nestas seis praças, apresentado valores abaixo de $115 \mathrm{~m}^{2}$ de projeção de cobertura. 


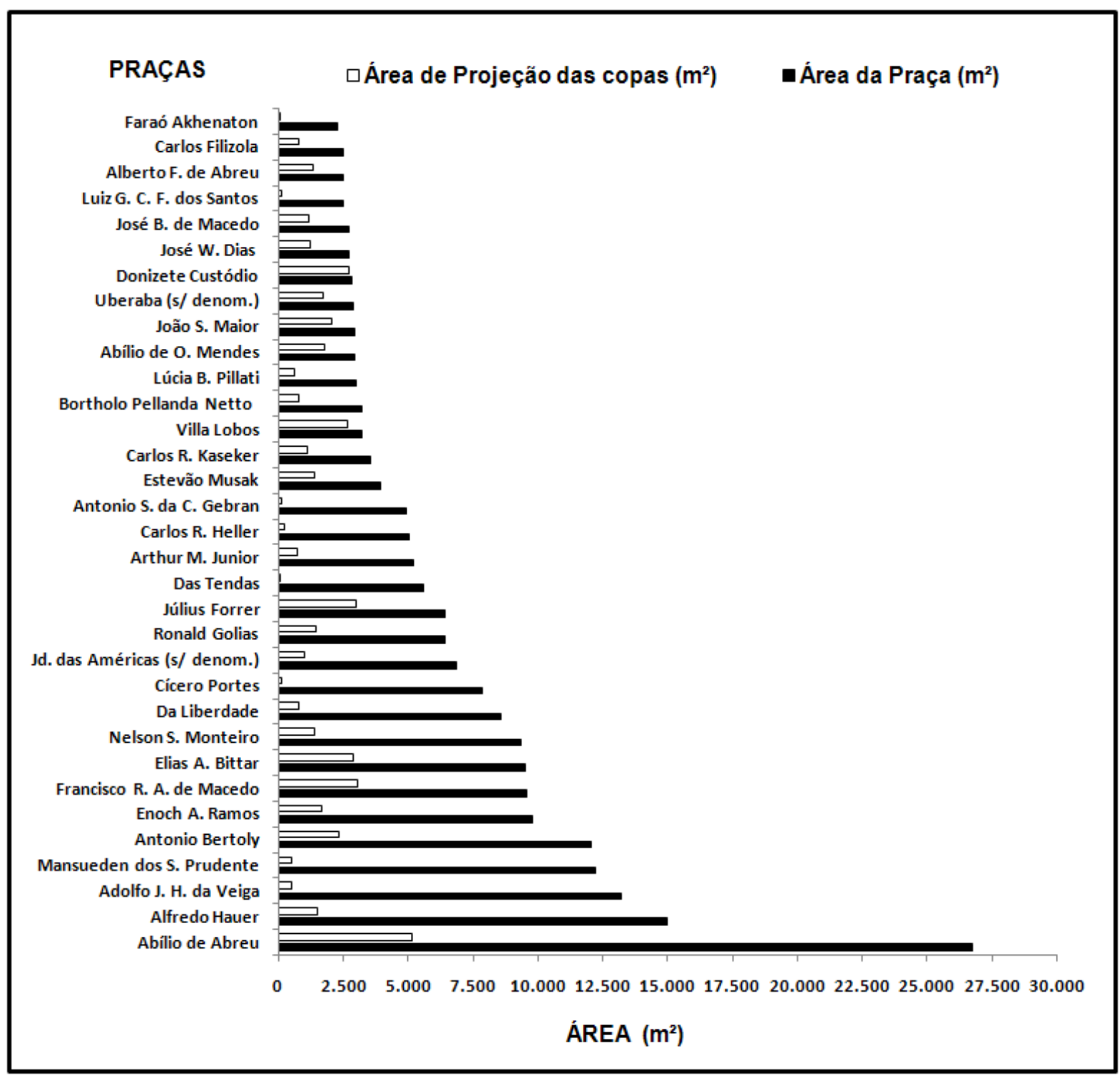

Figura 4. Áreas totais das praças de Curitiba em relação a área de projeção das copas Figure 4. Total area of Curitiba's squares with respect to the crown area projection

Apenas as praças Donizete Custódio, Villa Lobos e João S. Maior apresentaram áreas de projeção de copa proporcionais a área da praça.

Os resultados proporcionais da área de projeção da copa em relação à área das Praças estão representados na figura 5.

Observa-se que a média obtida foi de 1.392,62 $\mathrm{m}^{2}$, sendo que apenas seis praças apresentaram taxas de cobertura arbórea acima de $50 \%$, as outras 27 praças tiveram taxas abaixo desse valor.

Souza (2011), avaliando as áreas verdes urbanas na cidade de Recife, verificou que a média de cobertura arbórea era de apenas 6,68\%, sendo que a maior cobertura arbórea foi observada no Sítio da Trindade com 11,25\%. 


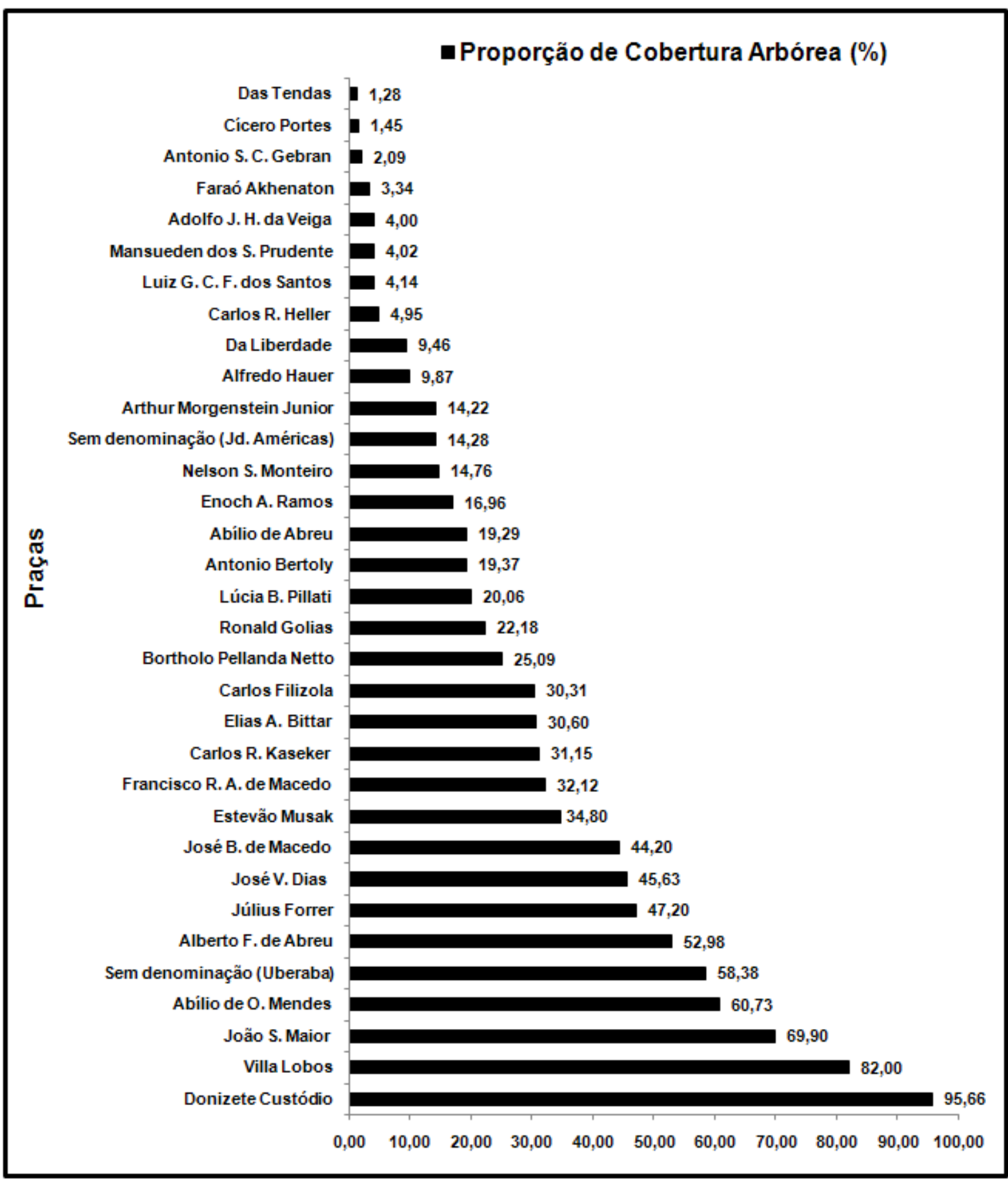

Figura 5. Proporção de cobertura arbórea das praças

Figure 5. Proportion of arboreal coverage of the squares

Lima Neto et al. (2007), avaliando as áreas verdes públicas do Centro de Aracaju - SE, encontraram em quatro praças públicas índices de sombreamento arbóreo (projeção de cobertura arbórea) entre $10,81 \%$ e $70,80 \%$, sendo que apenas a praça General Valadão apresentou índice abaixo do recomendado que é de 30\% para as áreas onde predominam comércio e 50\% para as áreas com o predomínio de residências. 
Baseado nos índices sugeridos pelos autores acima, inferimos que somente cinco praças (Donizete Custódio, Villa Lobos, Abílio de O. Mendes, Sem denominação - Uberaba, Alberto F. de Abreu) apresentaram taxas de cobertura arbórea acima de 50\%, conforme o recomendado para as áreas onde há o predomínio de residências, representando $15,15 \%$ do total da amostragem.

Ressalta-se ainda que apenas duas praças, José Borges de Macedo e João Souto maior, encontram-se inseridas em área com predomínio de comércio, apresentando taxas de cobertura de $44,20 \%$ e $69,90 \%$, respectivamente. Dessa forma, as mesmas exibiram valores acima de 30\%, sugerido para áreas comerciais, e correspondem 6,06\% do total da amostragem.

Sendo assim, apenas sete praças apresentaram taxas de cobertura aceitáveis, as outras 26 praças demonstraram índices de cobertura abaixo de 50\%, e representaram $21,21 \%$ e $78,79 \%$, respectivamente.

Com base nos resultados da amostragem e nos critérios recomendados de índices mínimos de cobertura arbórea, podemos inferir que as praças de Curitiba apresentam baixas taxas de cobertura florestal.

A Praça Donizete Custódio foi a que apresentou o maior valor de 95,66\%, seguida das Praças Villa Lobos e João S. Maior com valores de $82,00 \%$ e 69,90\%, respectivamente. Todavia, esses resultados podem estar superestimados, em razão do entrelaçamento das copas e da projeção da copa fora dos limites físicos das praças.

Nas Praças Donizete Custódio, Villa Lobos e João S. Maior destacam-se exemplares adultos e de grande porte de Parapiptadenia rigida (Benth.) Brenan (angico), Peltophorum dubium (Spreng.) Taub. (canafístula), Jacaranda mimosifolia D. Don (jacarandá-mimoso), Erythrina falcata Benth. (corticeira) e Ceiba speciosa (A.St.-Hil.) Ravenna (paineira), os quais possuem copas amplas e são espécies recomendadas no paisagismo de grandes jardins (figura 6).

Segundo Backes e Irgang (2004), as praças e parques são lugares ideais para o cultivo de espécies de grande porte, pois a extensão do espaço permite o pleno desenvolvimento de sua copa e a apreciação da árvore em sua beleza plena. 

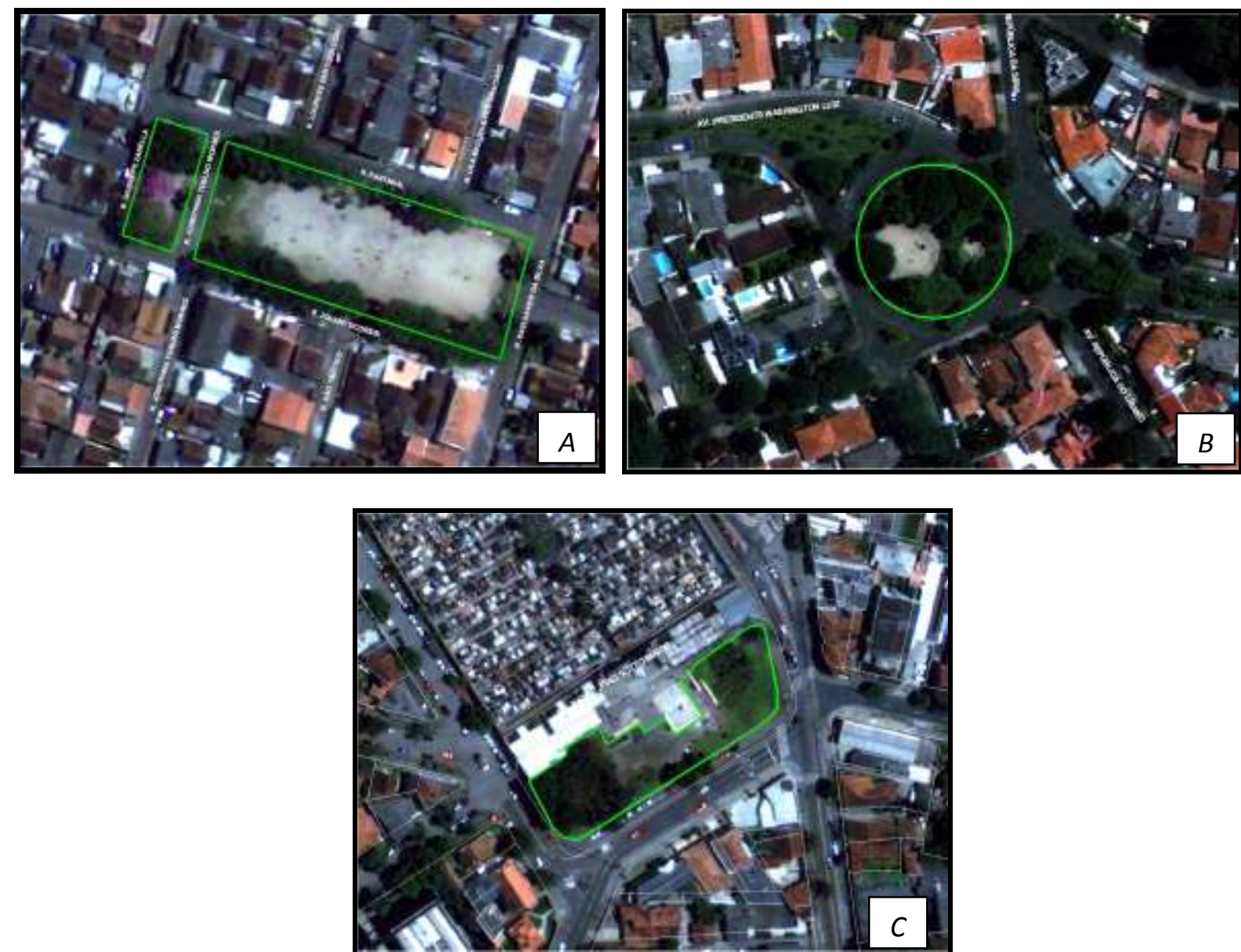

Figura 6. Praças com maiores proporções de projeção da copa em relação a área total: (a) Donizete C. da Silva, (b) Villa Lobos e (c) João Sotto Maior

Figure 6. Squares with highest proportions of crown projection of copa with respect to total area: (a) Donizete C. da Silva, (b) Villa Lobos and (c) João Sotto Maior

Os resultados obtidos para a densidade de copa em relação à área de cada parcela variaram de 9.566,07 $\mathrm{m}^{2} /$ ha para a praça Donizete Custódio e 128,44 $\mathrm{m}^{2} /$ ha para a praça da Tendas, com média de 2.807,46 m²/ha.

Bobrowski e Biondi (2012), analisando a estrutura e dinâmica da arborização de ruas de Curitiba, no período 1984 - 2010, encontraram valores de densidade de copa variando entre $125,09 \mathrm{~m}^{2} /$ ha e 1.037,85 m²/ha. Assim, 23 praças apresentaram valores de densidade de copa acima dos encontrados na arborização de ruas de Curitiba.

\section{CONCLUSÕES}

A área total de cobertura das copas das praças apresentou o valor de 45.956,55 m², destacando-se a Praça Abílio de Abreu com 5.151,35 $\mathrm{m}^{2}$. Entretanto, a Praça Donizete Custódio apresentou a maior taxa de cobertura na relação entre a área de projeção da copa e 
a área total, com 95,66\%, seguida das Praças Villa Lobos e João Souto Maior, com valores de $82,00 \%$ e 69,90 , respectivamente.

Os menores valores obtidos foram para as praças das Tendas e Cícero Portes com $1,28 \%$ e $1,45 \%$, respectivamente.

Apenas sete praças apresentaram índices de cobertura arbórea aceitáveis, representando $21,21 \%$, as outras 26 praças demonstraram índices de cobertura abaixo de $50 \%$ e representaram $78,79 \%$ do total amostrado.

Com base nos resultados da amostragem e nos critérios recomendados de índices mínimos de cobertura arbórea, pode-se inferir que as praças de Curitiba apresentam baixas taxas de cobertura arbórea.

\section{REFERÊNCIAS}

ALCANTARA, M. A. DOS R.; VAZQUEZ, G. H. Caracterização paisagística e da frequência de usuários de duas praças centrais de Caraguatatuba/SP. Revista da Sociedade Brasileira de Arborização Urbana, Piracicaba - SP, v. 10, n. 3, p. 38-59, 2015.

BACKES, P.; IRGANG, B. Árvores cultivadas no sul do Brasil: guia de identificação e interesse paisagístico das principais espécies exóticas. Porto Alegre: Palotti, 2004, 204 p.

BARGOS, D. C.; MATIAS, L. F. Áreas verdes urbanas: um estudo de revisão e proposta conceitual. Revista da Sociedade Brasileira de Arborização Urbana, Piracicaba - SP, v. 6, n. 3, p. 172-188, 2011.

BIONDI, D.; LIMA NETO E. M. Distribuição espacial e toponímia das praças de Curitiba. Revista da Sociedade Brasileira de Arborização Urbana, Piracicaba - SP, v. 7, n. 3, p.31-43, 2012.

BOBROWSKI, R.; BIONDI, D. Distribuição e dinâmica da área de copa na arborização de ruas de Curitiba, Paraná, Brasil, no período de 1984 - 2010. Revista Árvore, Viçosa-MG, v. 36, p. 625-635, 2012.

CURITIBA. Prefeitura Municipal de Curitiba. Legislação SMMA. Disponível em: < http://www.curitiba.pr.gov.br/conteudo/legislacao-smma/347.> Acesso em: 21/06/2012.

CURITIBA. Prefeitura Municipal de Curitiba. Maciços florestais. Disponível em: <http://www.curitiba.pr.gov.br/noticias/indice-de-area-verde-passa-para-645-m2-porhabitante/25525.> Acesso em: 19/08/2012.

HARDER, I. C. F.; RIBEIRO, R. DE C. S.; TAVARES, A. R. Índices de área verde e cobertura vegetal para as praças do município de Vinhedo, SP. Revista Árvore, Viçosa, MG, v. 30, n. 2, p. 277-282, 2006.

INSTITUTO PESQUISA E PLANEJAMENTO URBANO DE CURITIBA (IPPUC) Curitiba em dados. Disponível em: <http://curitibaemdados.ippuc.org.br/Curitiba_em_dados_Pesquisa.htm> Acesso em: 25/10/2011. 
LEAL, L.; ALMEIDA, A. M. R.; BIONDI, D.; NETO, E. M. L.; MARTINI, A. Microclima de tipologias paisagísticas do Parque Municipal Tingui, Curitiba, Paraná. Revista Geografar. Curitiba, PR, v. 9, n. 1, p. 8-26, jun./2014.

LEAL, L.; BIONDI, D.; BATISTA, A. C. Efeitos da vegetação na variação térmica da cidade de Curitiba, PR. Revista Floresta, Curitiba - PR, v. 44, n. 3, p. 451-464, jul./set. 2014.

LIMA NETO, E. M; RESENDE, W. J.; SOUZA, R. M. Áreas verdes púbicas do centro de Aracaju - SE: análise fitogeográfica, Revista da Fapese, Aracaju - SE, v. 3, n. 2, p. 5-16, 2007.

LIMA NETO, E. M; SILVA, M. Y. B.; SILVA, A. R.; BIONDI, D. Arborização de ruas e acessibilidade no bairro centro de Curitiba - PR Revista da Sociedade Brasileira de Arborização Urbana, Piracicaba - SP, v. 5, n. 4, p. 40-56, 2010.

MARTINI, A.; BIONDI, D.; BATISTA, A. C.; ZAMPRONI, K. Valores extremos do índice de conforto térmico nas ruas de Curitiba-PR: comparação entre ambientes arborizados e sem arborização. Revista da Sociedade Brasileira de Arborização Urbana, Piracicaba - SP, v. 8, n. 3, p. 52-62, 2013.

MARTINI, A.; BIONDI, D. Microclima e conforto térmico de um fragmento de floresta urbana em Curitiba, PR. Revista Floresta e Ambiente, v. 22, p. 182-193, 2015.

MARTINS, L. F. V.; ANDRADE, H. H. B; HANISCH, R. F.; DE ANGELIS, B. L. B.; CAXAMBU, M. G. Análise da compatibilidade da arborização viária com ambiente construído na cidade de Luiziana, Paraná, Brasil. Revista da Sociedade Brasileira de Arborização Urbana, Piracicaba - SP, v. 6, n. 3, p. 103-127, 2011.

ROBBA, F.; MACEDO, S. S. Praças brasileiras: Public Squares In Brazil. 3.ed. São Paulo: Editora da Universidade de São Paulo, 2010- [Coleção Quapá].

REDIN, C G.; VOGEL, C.; TROJAHN, C. D. P.; GRACIOLI, C. R.; LONGHI, S. J. Análise da arborização em cinco praças do município de Cachoeira do Sul - RS. Revista da Sociedade Brasileira de Arborização Urbana, Piracicaba - SP, v. 5, n. 3, p. 149-165, 2010.

SOUZA, W. Caracterização da cobertura arbórea dos parques urbanos da cidade de Recife - PE. 100 f. Tese (Doutorado em Ciências Florestais) Departamento de Ciência Florestal, Universidade Federal Rural de Pernambuco, Recife, 2011.

SILVA, I. M. DA; GONZALEZ, L. R.; SILVA FILHO, D. F. DA. Recursos naturais de conforto térmico: um enfoque urbano. Revista da Sociedade Brasileira de Arborização Urbana, Piracicaba - SP, v. 6, n. 4, p. 35-50, 2011.

SILVA, R. N. DA; GOMES, M. A. S. Comparação quali-quatitativa da arborização em espaços públicos da cidade de Arapiraca - AL. Revista da Sociedade Brasileira de Arborização Urbana, Piracicaba - SP, v. 8, n. 2, p. 104-117, 2013.

VIEIRA, C. H. S. D.; BIONDI, D. Análise da dinâmica da cobertura vegetal de Curitiba, PR (de 1986 a 2004), utilizando imagens Landsat TM. Revista Árvore, Viçosa - MG, v. 32, n. 3, p. 479-487, 2008. 